TecnoLógicas

ISSN 0123-7799

ISSN-e 2256-5337

Vol. 20, No. 39

Mayo- agosto de 2017

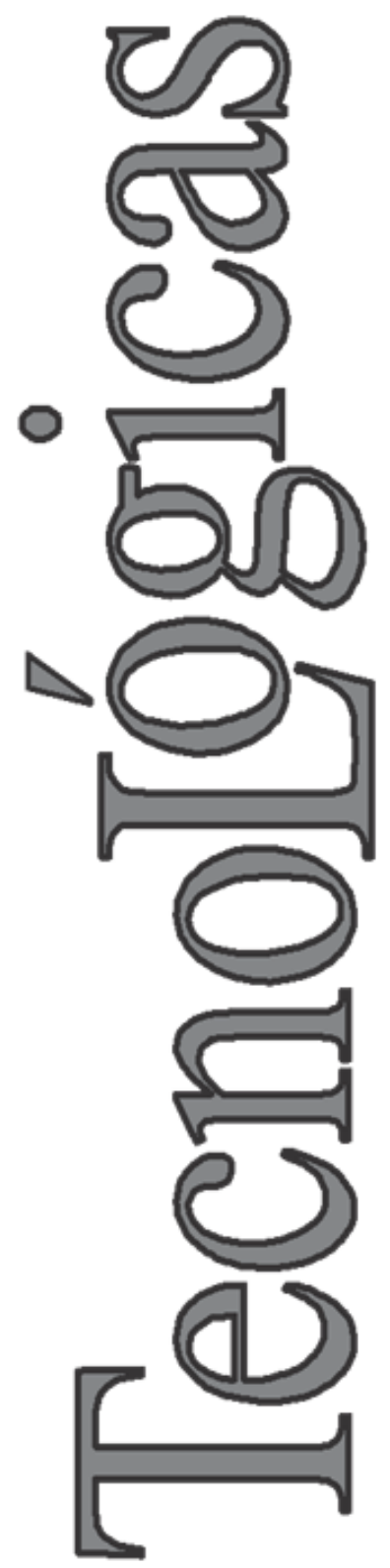

(C) Copyright 2015 por autores y Tecno Lógicas Este trabajo está licenciado bajo una Licencia Internacional Creative Commons Atribución (CC BY)

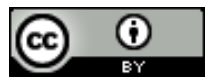

\section{Analysis of the efficiency of a virtual- optical multiplexing method, by using theta modulation}

\author{
Análisis de la eficiencia de un método de \\ multiplexado óptico-virtual, usando \\ modulación teta
}

Javier Vargas Valencia ${ }^{1}$

Recibido: 02 de abril de 2017,

Aceptado: 03 de mayo de 2017

Cómo citar / How to cite

J. Vargas-Valencia, "Analysis of the efficiency of a virtual-optical multiplexing method, by using theta modulation", TecnoLógicas, vol. 39, no. 20, 2017.

\footnotetext{
1 PhD in Physics, Grupo de Investigación GRITAD, Instituto Tecnológico Metropolitano, Medellín-Colombia, javiervargas@itm.edu.co
} 


\section{Abstract}

We present an efficient virtual-optical multiplexing method for compressing information contained in gray level images. The efficiency is measured using three parameters: quality factors of recovered images, memory saving percentage achieved, and number of multiplexed images in the package. Theta modulation techniques are applied, to process an $\mathrm{N}$ number of gray level images, by using a virtual-optical $2 \mathrm{f}$ architecture, from which we obtain a complex package $M$, to be stored as two images, amplitude and phase, in commercial formats. We apply pixel optimization and Fourier plane filtering to amplitude and phase images, respectively, storing only a percentage of the Fourier plane with a pixel dynamic range optimization. The stored package spends much less memory than individual images. The recovered images after the demultiplexing process are compared with the original ones by using correlation coefficient, obtaining high quality factors for decompressed images. We perform simulations, showing the efficiency of the proposed process, and our results are compared to the same factors reported in recent publications, making our improvements evident.

\section{Keywords}

Image multiplexing, Data Compress, Fourier Transform, Theta modulation, optodigital simulation.

\section{Resumen}

Presentamos un método de multiplexado óptico-virtual eficiente, para comprimir información contenida en imágenes en niveles de gris. La eficiencia se mide usando tres parámetros: Factores de calidad de las imágenes recuperadas, porcentaje de memoria ahorrada, y número de imágenes multiplexadas en el paquete. Se aplican técnicas de modulación teta, procesando un número $\mathrm{N}$ de imágenes en niveles de gris, usando una arquitectura óptico-virtual $2 \mathrm{f}$, obteniendo un paquete complejo $\mathrm{M}$, que es almacenando como dos imágenes, amplitud y fase de $\mathrm{M}$, en formatos comerciales. Se aplica un filtrado al plano de Fourier y una optimización a los píxeles de las imágenes de amplitud y fase, respectivamente, almacenando solo un porcentaje del plano de Fourier con una optimización al rango dinámico para los píxeles de cada una de ellas. El paquete almacenado gasta mucho menos memoria que las imágenes individuales. Las imágenes recuperadas después del proceso de desmultiplexado se comparan con las originales mediante el coeficiente de correlación, obteniendo para las imágenes recuperadas factores de calidad altos. Se realizan simulaciones que muestran la eficiencia del proceso propuesto, y nuestros resultados son comparados con los mismos factores reportados en publicaciones recientes, haciendo evidentes los avances logrados en este trabajo.

\section{Palabras clave}

Multiplexado de imágenes, Compresión de datos, Transformada de Fourier, Modulación teta, Simulación óptico-digital. 


\section{INTRODUCTION}

Virtual-optical methods for information processing are a new alternative for optimizing and solving modern problems such as the storage and transmission of large amounts of information contained in image files, and for data in general, for both scientific and commercial purposes, among others. In particular, image multiplexing and processing for high volumes of information contained in gray level (GL) images, by using virtual-optical techniques have been investigated in recent years [1]-[15], where optical process are simulated looking for storing the information compressed in a package, which is, in general, complex. The usual procedures involve some virtualoptical architecture, like 2f, 4f, JTC, etc, and its purpose is to take a number of $\mathrm{N}$ images and to compress all of them in a package. In many cases, other additional encryption processes are performed to the package, but we are only interested in the multiplexing or compressing processes of these works. Then, the way in which the package is stored, and the quality factor of recovered information, play a fundamental role in the possible efficiency achieved by the method. We are interested in the efficiency of such processes, and with this in mind, we have made a revision of the main scientific published results in this area, looking for establishing possible factors to evaluate the efficiency of these virtualoptical multiplexing methods. We consider that to get the efficiency in the multiplexing process is fundamental to obtain memory saving with the storing of the package, with respect to the memory spent for the $\mathrm{N}$ original images. On the other hand, the efficiency also must depend on the acceptable or suitable quality factors for the recovered information. The storing and transmission for large volumes of information is not just a commercial issue, but it is also a question for computation itself. Implementing opto-digital methods is shown as an alternative that could mean significant savings in physical memory for information storage and transmission with a high quality factor of recovered information.

Nowadays there exists several formats to compress information which are widely known as the ZIP and the RAR. Some of them are exclusively made to compress images, like the JPG format. In the case of GL images, that are the ones that have been compressed in this work, the most efficient is the RAR format. This one offers a reduction of approximately $38 \%$ of the memory occupied by the original images. However, in this work we are focused on virtual-optical methods, and works we will analyze here are based on this type of techniques.

The published results by H. E. Hwang et al [14], show a maximum number of GL images, $\mathrm{N}=10$, and illustrate an evident decreasing of correlation coefficient (CC) quality factor when increasing the $\mathrm{N}$ image number, obtaining an approximately value $\mathrm{CC}=0.93$ for $\mathrm{N}=10$. Other case to consider is the work by H. T. Chang et al [15], in which they evaluate the $\mathrm{CC}$ factor vs the $\mathrm{N}$ number of images in the multiplexed package, reaching a quality value $\mathrm{CC}=0.82$ for $\mathrm{N}=9$. Also, in this case, the quality factor $\mathrm{CC}$ decreases as $\mathrm{N}$ increases. In none of the two cases above is shown an evaluation of the percentage of memory saved obtained by their procedures. A known technique for image or information multiplexing is called theta modulation, it uses amplitude or phase gratings to separate the image information in demultiplexing stage. In the former work by Armitage [16], the gratings are introduced for information multiplexing under the concept of theta modulation, where the incline angle of the grating is proportional to the spatial frequency of the wave associated with each multiplexed message. In this work, two signals are multiplexed under this technique, and the authors do not present quality evaluation, neither storage memory saving achieved. More recently, Cabezas et 
al [3] proposed the use of a virtual-optical method, implementing amplitude sinusoidal gratings along with a $2 \mathrm{f}$ system to multiplex GL images avoiding crosstalk and by showing a reduction of package storage memory compared to the memory occupied by the individual images. They report a maximum number of $\mathrm{N}=12$ images and a percentage of memory savings of approximately $89 \%$, and do not report quality factors. Subsequently, these same authors report improvements with respect to the number of images, by using phase gratings instead of amplitude gratings, and use Normalized Root Mean Square Error (NRMSE) as quality factor; yet, a more complex architecture is used, consisting of a $4 \mathrm{f}$ system for multiplexing and an $8 \mathrm{f}$ system for demultiplexing stage [4]. In this work, they do not report memory savings, but, they show an increment of the image number to $\mathrm{N}=24$, and reporting some quality values as NRMSE $=0.30$ and 0.36 for two images. Those same techniques based on theta modulation were used by Mosso et al to multiplex and encrypt a complete video composed by GL images [17], while Barrera [18] and Trejos [19] claim for the use of a JTC system to make experimental multiplexing binary image messages in which the output plane presents location features similar to the ones exposed by Cabezas et al. in their works [3], [4].

In our previous work, we studied the effects of the quantization and transformation of pixel values of amplitude and phase images for a multiplexed package, and also the filtering of the Fourier plane (FP), in an information compression method via theta modulation techniques [20]. We have used virtual-optical simulations for multiplexing and demultiplexing image information based on a 2 f-correlator architecture and phase gratings. The memory savings achieved and quality factor CC for demultiplexed information were shown for three kinds of images: binary characters, QR codes, and GL human faces. In the present work we apply our compressing information method by using theta modulation techniques and an optimized procedure to store a complex multiplexing function $\mathrm{M}$, and we also report new achievements about efficiency terms mentioned above. We make a Fourier transform (FT) to every image and then we multiply this FT by its corresponding special phase function: a positioning diffraction grating (PDG) that permits us locate the information in the output plane in demultiplexing stage. The sum of all these products constitutes the complex package $\mathrm{M}$. The package $M$ is made up of two images: amplitude and phase, in this work, for the first time we use commercial image formats to store amplitude and phase of the package. The procedure to demultiplex the information of the nth image consists of using the complex conjugate (cc) of the nth grating, and multiplying it to the package, before the computing of the inverse Fourier transform. We compare the memory used to store the individual images and the package. The recovered information is compared to the original one by using the correlation coefficient $\mathrm{CC}$ as quality factor. All these parameters permit us to compare our results with the ones reported in recent publications.

\section{THETA MODULATION METHOD AND PACKAGE OPTIMIZATION}

\subsection{Multiplexing-demultiplexing method}

The multiplexing process used is based on theta modulation techniques. It can be summarized as it is shown in fig. 1. In order to pack $N^{\text {th }}$ images in a complex package M, a FT is performed over each image $I_{k}$, obtaining a $P_{k}$ complex function, where $P_{k}=\mathrm{FT}\left\{I_{k}\right\}$, and then, it is multiplied by its respective positioning diffraction grating (PDG), $R_{k}$, obtaining $J_{k}=P_{k}$ $R_{k}$. The sum of all these products constitutes the complex package $\mathrm{M}$, represented in (1): 
$M=\sum_{k} P_{k} R_{k}=\sum_{k} J_{k}$

The phase function or PDG, $R_{k}$, is given in terms of: wavelength, the propagation distance $z$ between input and output planes, and the localization images central point in output plane of demultiplexing process $\left(a_{k}, b_{k}\right)$ as in (2).

$R_{k}(x, y)=e^{-2 i \pi a_{k} \frac{x}{\lambda z}} e^{-2 i \pi b_{k} \frac{y}{\lambda z}}$

These phase functions like in (2), are usually called gratings in recent publications and our treatment is similar to the one used by them [3], [4]. More deeply explanations about gratings can be seen in the classical book by Goodman [21]. The demultiplexing process can be simulated as an optical $2 \mathrm{f}$ system, and it consists of using a lens to perform the optical Fourier Transform of the multiplexed package, which, in an experimental stage is digitally manipulated before introducing it through amplitude and phase modulators in the input plane of the demultiplexing system. In this case the propagation distance $\mathrm{z}$ in (2) is the focal distance of the lens of the $2 f$ system. To demultiplex the image number $k$, package $\mathrm{M}$ is multiplied by the $c c$ of the corresponding PDG, $R_{k}{ }^{*}$. A propagation of the product $\mathrm{M} R_{k}{ }^{*}$ through the $2 \mathrm{f}$ system is equivalent to an inverse FT, and give us the output $k$-image at the center of the output plane. The inverse $\mathrm{FT}$ of $\mathrm{M} R_{k} *$ is given by expression (3).

$L_{k}=F T^{-1}\left(M R_{k}^{*}\right)=F T^{-1}\left\{\left(\sum_{l} F T\left[I_{l}\right] R_{l}\right) R_{k}^{*}\right\}$

We distribute this sum of inverse FT, knowing that the inverse FT for each product in the sum is the convolution product of individual FT_s. We obtain a known function in terms of Dirac deltas. Then, $k$-th image is located by Dirac deltas in a spatial region well separated from each other, avoiding crosstalk. The $L_{k}$ function is written for each image $I_{k}$ as in the following expression:

$L_{k}=I_{1}\left(x+a_{1}-a_{k}, y+b_{1}-b_{k}\right)+\cdots+I_{k}(x, y)+\cdots+I_{N}\left(x+a_{N}-a_{k}, y+b_{N}-b_{k}\right)$

Every term in (4) is located in different regions of the output plane, and its center is located by the PDG, concluding that, for every $\mathrm{k}^{\prime} \neq \mathrm{k}$, the image $I_{k}$ ' has its center located at the point $\left(a_{k^{\prime}}-a_{k}, b_{k^{\prime}}-b_{k}\right)$, while the image $I_{k}$ is located at the center of the output plane. Finally, the desired information $I_{k}$ can be selected by filtering only the center of the output plane. In fact, this is an advantage of our method, because we only need an output plane as big as a single image, while other methods need much more space in the output plane. Filtering the output plane, selecting a small region ||$L_{k}||$, as big as a single image, we obtain only the image $I_{k}$, as in (5). This is the image which is compared to the corre- sponding original one, by using $\mathrm{CC}$ as quality factor.

$\left\|L_{-} k\right\|=I_{-} k(x, y)$

\subsection{Package storing optimization}

Following the procedure recently reported in publication [20], in Fig. 2, we show some examples of faces images that we want to store.

The theta modulation method described above, is applied to compress quantities of $\mathrm{N}=49,121,225,361,529$ and 721 images of human faces, $256 \times 256$ pixels in size. In each case the package is composed by two images concerning amplitude and phase. 
The next stage to optimize the package is the quantization and transformation of amplitude $\mathrm{A}$ and phase $\mathrm{P}$ images for each one of the packages in the different $\mathrm{N}$ cases. Also the redundant information due to the analyzed symmetries of amplitude and phase images, is removed, and we finally store the optimized images $\mathrm{A}$, and $\mathrm{P}$, shown in Fig. 3 as an example, for $\mathrm{N}=121$ images in package.

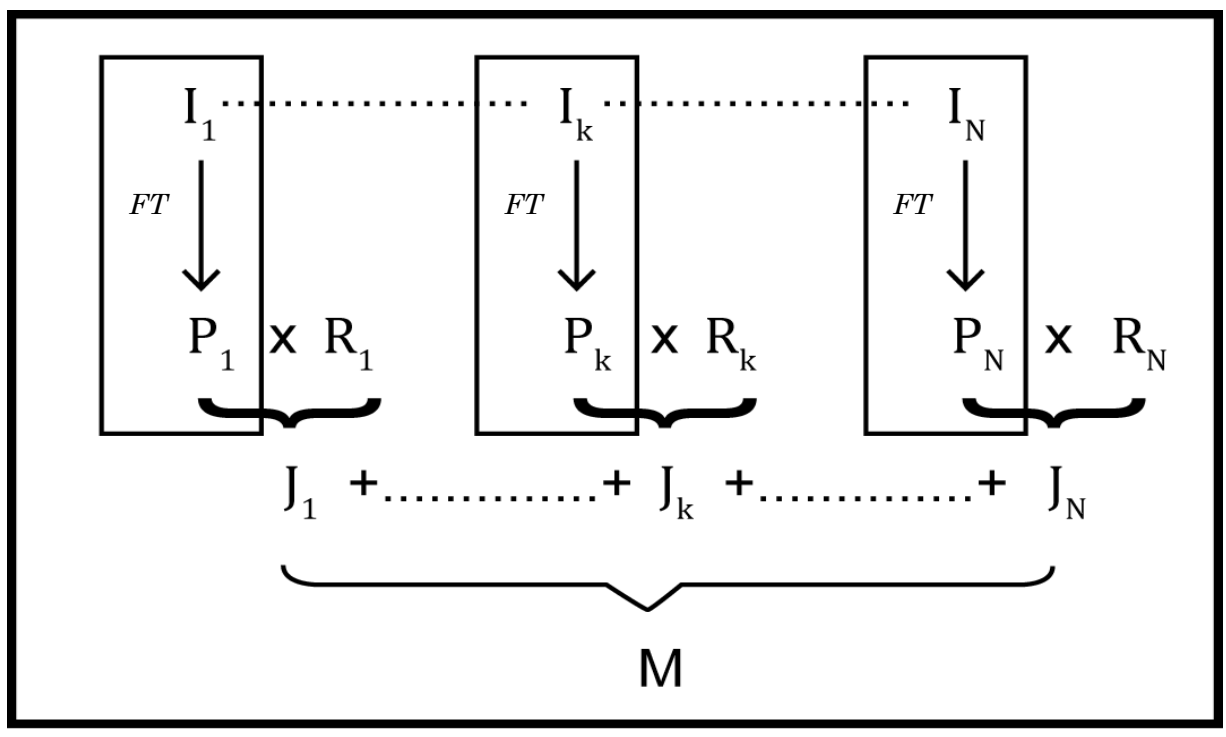

Fig. 1. Summary of multiplexing method for $\mathrm{N}$ images to compress in the complex package M. Source: Author.
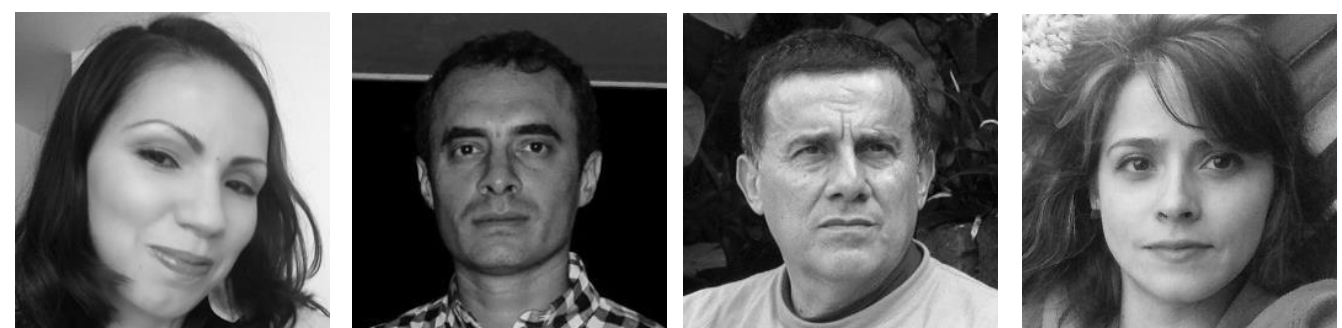

Fig. 2. Human faces, examples of GL images to compress. Source: Author.
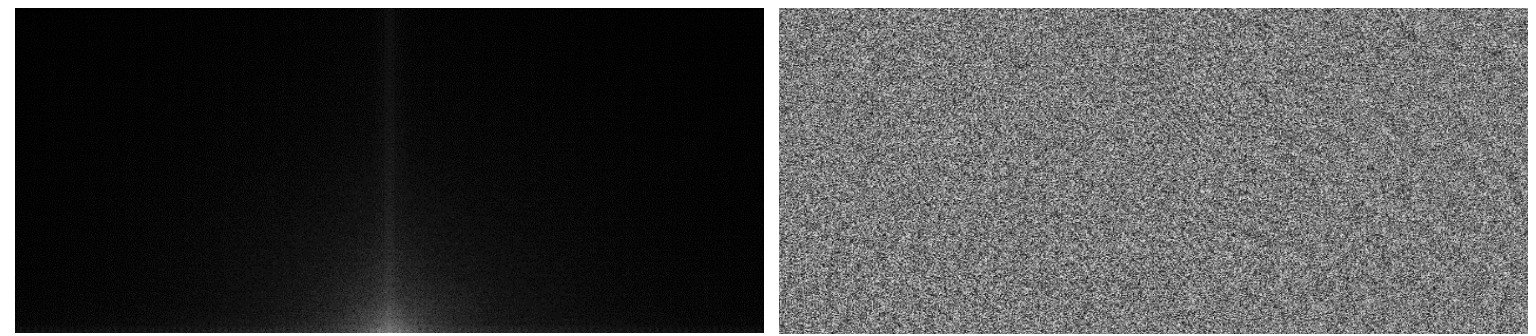

Fig. 3. Examples of final images $\mathrm{A}$ and $\mathrm{P}$ of package after optimization process, stored in commercial image format PNG, for $\mathrm{N}=121$. Source: Author. 


\subsection{Efficiency}

The aspects that play an important role in the optimization of efficiency of the method for compressing information, reducing the storing memory and retaining image quality for recovered information, are: The filtering of FP, the optimization of dynamic range through logarithmic transformation and bit quantization for pixels of amplitude and phase, and finally, the elimination of redundant information thanks to the symmetries of amplitude and phase. The criterion by which the efficiency of a compression method can be measured is based on its power to store information by reducing the required storage memory to the package and obtaining recovered information whose quality indexes are measurable and reach suitable values. The percentage of saved storage memory (S) has an ideal maximum limit of $100 \%$, and it is calculated as in (6):

$S=100\left(1-\frac{V_{M}}{\sum_{l} V_{l}}\right)$

where $V_{M}$ is the memory occupied by the package in $\mathrm{KB}$, while $V_{i}$ is the memory occupied by the original image $i$, also in $\mathrm{KB}$. It is clear that reaching a higher value for $\mathrm{S}$ depends on decreasing the ratio $V_{M} / \Sigma V_{i}$, as much as possible. All of this, will contribute to the optimization of memory. The quality of the retrieved information can be measured by the correlation coefficient (CC) expressed in (7), which compares the recovered image with the original one, and which can have values between -1 and +1 , with +1 being the ideal value that implies that the recovered image is identical to the original.

$C C=\frac{\sum_{i} \sum_{j}\left(x_{i j}-\bar{x}\right)\left(y_{i j}-\bar{y}\right)}{\sqrt{\sum_{i} \sum_{j}\left(x_{i j}-\bar{x}\right)^{2} \sum_{i} \sum_{j}\left(y_{i j}-\bar{y}\right)^{2}}}$ where $x_{i j}$ are the values of each pixel of the original image, while $y_{i j}$ are the pixel values of the recovered image. To measure the efficiency $E_{c}$ of the method we propose to take into account the percentage of memory saved and the average quality factor of the $\mathrm{N}$ images in the package as expressed in (8). The efficiency reaches an ideal limit value of $100 \%$, and it is measured as the product of these two factors:

$E_{c}=\overline{C C} S$

where $\overline{C C}$ is the average value of the $\mathrm{CC}$ quality factor for the $\mathrm{N}$ images in the package. Another factor contributing to the optimization of the efficiency $E_{c}$, is the number $\mathrm{N}$ of images in the package. In the revised works published in this area [13][15], [22], it is evident that increasing the number of images always decreases the average CC quality factor of the multiplexed $\mathrm{N}$ images. Another factor of quality to be considered for possible comparisons is the Normalized Root Mean Square Error NRMSE, which is defined in (9), where $x_{i j}$ are the pixel values of the original image, and $y_{i j}$ are the pixel values of the recovered image.

$N R M S E=\frac{\left[\sum_{i} \sum_{j}\left(x_{i j}-y_{i j}\right)\right]^{2}}{\sum_{i} \sum_{j}\left(x_{i j}\right)^{2}}$

\section{RESULTS AND DISCUSSION}

We apply our previous cited multiplexing method to compress several quantities of N GL images of human faces, 256x256 pixels in size. In the analyzed cases, we filter the FP, cutting only the percentage FP, taken from its center, and making an optimization process before storing the amplitude and phase images of package $\mathrm{M}$. We analyze three cases, in which the FP filtering is different. As the percentage of filtered FP decreases, the quality of the recovered information diminishes, since 
the increasing of the loss of high frequencies is obvious, but, we gained in reduction storage memory.

\subsection{Case 1. Filtering $40 \%$ of FP}

We store $40 \%$ of the PF, with optimization values defined in our previous cited work, NA=4096, NUQ $=255, \mathrm{NF}=255$. The package consists in two images, $\mathrm{A}$ and $\mathrm{P}$ of $\mathrm{M}$, which are stored in image $\mathrm{PNG}$ format, whose choice was the result of an optimization process, which involves choosing a lossless format available commercially, easily accessible, and with 8 bitdepth. These characteristics were optimized in [20], [21], [23], looking for the package to occupy the smallest possible memory space. Fig. 4 shows the average CC behavior as a function of the number of $\mathrm{N}$ images in the package.
The compression and decompression processes are performed to the $\mathrm{N}$ images, performing the measurement of the $\mathrm{CC}$ to each recovered image, and comparing it to the original one, and calculating the average $\mathrm{CC}$ for each package containing $\mathrm{N}$ images. Our results indicate that the average $\mathrm{CC}$ value for the $\mathrm{N}$ images of the package is maintained above 0.993 even though the $\mathrm{N}$ number increases. In Table 1 we can see some examples of images recovered in each case.

Note that with the naked eye there are no changes in the information retrieved although $\mathrm{N}$ increases noticeably. These results are novel insofar as we do not know published results that show an $\mathrm{N}$ number of images in the package as high as the one we have achieved, maintaining the quality in the recovered information.

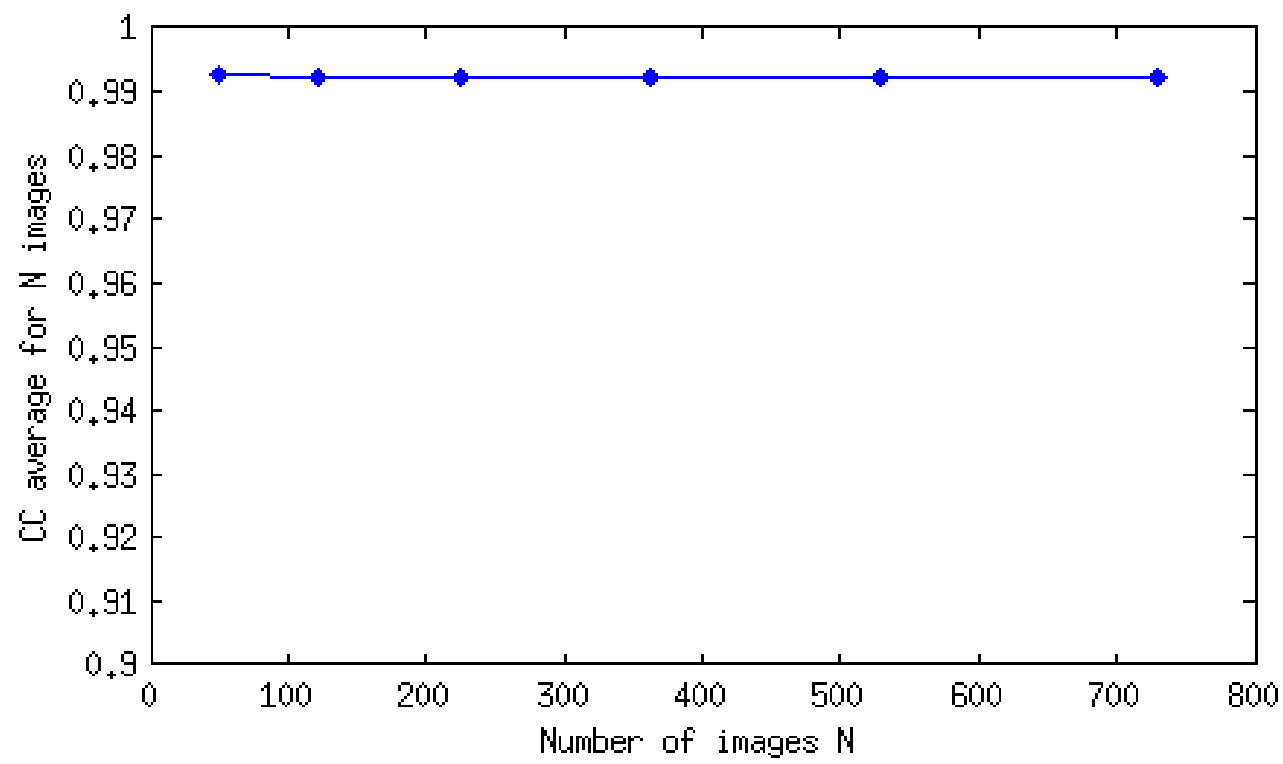

Fig. 4. CC average against the number $\mathrm{N}$ of images in the package. Source: Author. 
Table 1. Examples of recovered images from package after demultiplexing process, filtering $40 \%$ of FP. Source: Author.
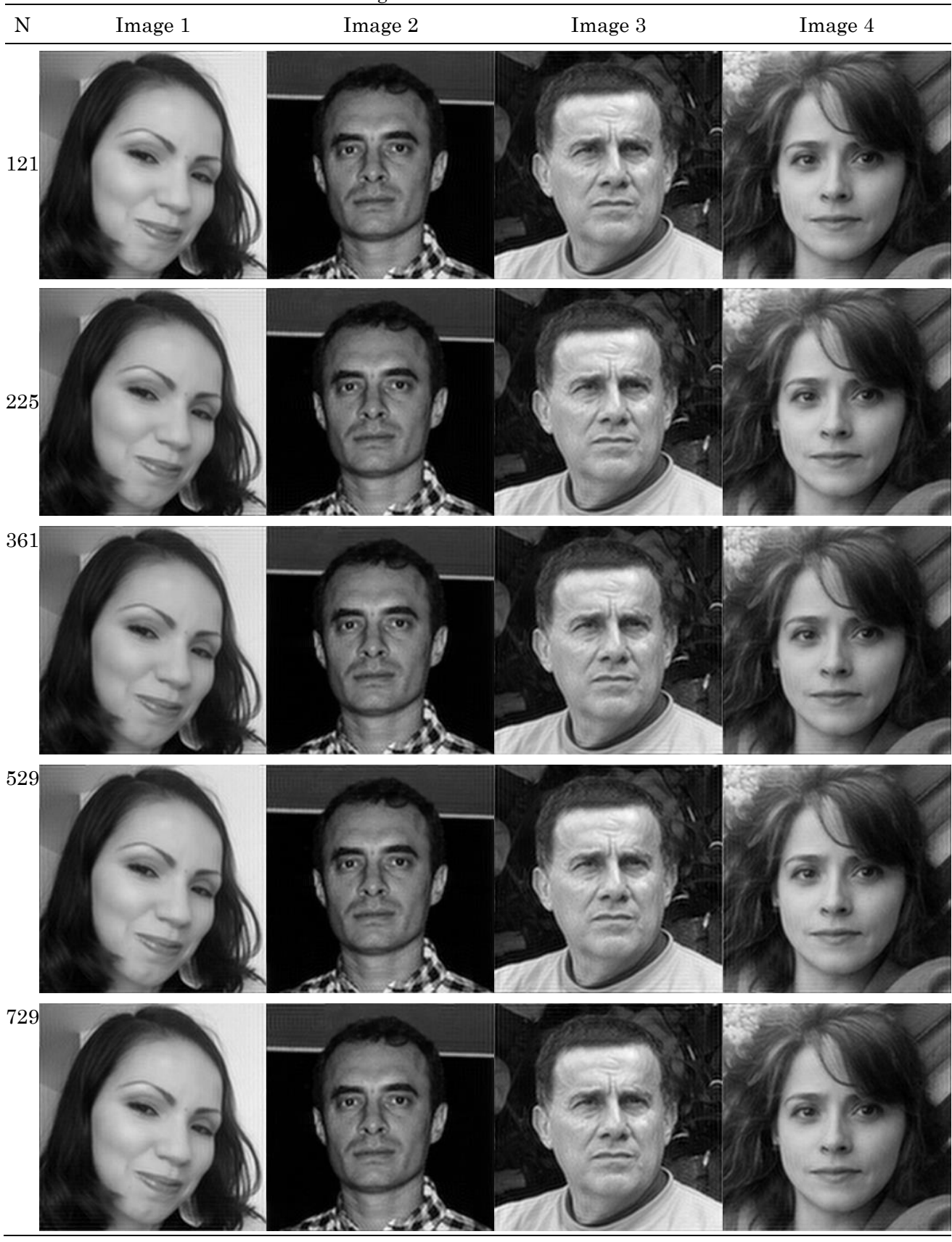

One of the advantages of our method is the use of a commercial format like PNG (or any other lossless format) to store the package, which facilitates its manipulation, storage and transmission. Now, the complete results of this process, in terms of memory saving and image quality are summarized in the Table 2 , in which they appear, from left to right: number $\mathrm{N}$ of images in package, memory $V_{M}$ spent for the package in $\mathrm{A}$ and $\mathrm{P}$ processed images, memory expended for individual $\mathrm{N}$ images $\Sigma V_{i}$, percentage of memory saving achieved $\mathrm{S}$, and $\overline{C C}$ average value obtained. 
Table 2. Summary of memory saving reached and quality factors of recovered images,storing $40 \%$ of FP.

\begin{tabular}{ccccc}
\multicolumn{5}{c}{ Source: Author. } \\
\hline $\mathrm{N}$ & $V_{M}(\mathrm{~KB})$ & $\Sigma V_{i}(\mathrm{~KB})$ & $\mathrm{S}(\%)$ & $\overline{C C}$ \\
\hline 49 & 400 & 1764 & 77.32 & 0.993 \\
121 & 976 & 4368 & 77.66 & 0.993 \\
225 & 1740 & 8124 & 78.58 & 0.992 \\
361 & 2738 & 12944 & 78.85 & 0.993 \\
529 & 3937 & 18992 & 79.27 & 0.992 \\
721 & 5360 & 24912 & 78.48 & 0.992 \\
\hline
\end{tabular}

The memory spent to store the information of the package images is much less than the one spent for all the $\mathrm{N}$ images. In this case, the average efficiency reached for all cases is the product of average values of terms $\mathrm{S}$ and $\overline{C C}: E_{c}=77.9 \%$.

\subsection{Case 2. Filtering $30 \%$ of FP}

We store in this case $30 \%$ of the FP. Having the parameters $\mathrm{NA}=4096, \mathrm{NUQ}=$ $255, \mathrm{NF}=255$. The stored package is saved again in image PNG format with 8 bitdepth. The quality of the retrieved information decreases as the percentage of the stored FP decreases, as in this case, but the storage memory saving increases, as is shown in Table 3, where the results of this case are summarized.

Table 3. Summary of memory saving reached and quality factors of recovered images, storing $30 \%$ of FP. Source: Author.

\begin{tabular}{ccccc}
\hline $\mathrm{N}$ & $V_{M}(\mathrm{~KB})$ & $\Sigma V_{i}(\mathrm{~KB})$ & $\mathrm{S}(\%)$ & $\overline{C C}$ \\
\hline 49 & 232,1 & 1764 & 86.84 & 0.988 \\
121 & 566 & 4368 & 87.04 & 0.988 \\
225 & 1031 & 8124 & 87.31 & 0.988 \\
361 & 1598 & 12944 & 87.65 & 0.988 \\
529 & 2311 & 18992 & 87.83 & 0.988 \\
721 & 3119 & 24912 & 87.48 & 0.988 \\
\hline
\end{tabular}

Also it can be seen the increasing in the memory saving percentage $\mathrm{S}$, and the decreasing in the quality value of the recovered $\overline{C C}$ information respect to larger percentage of filtered $\mathrm{FP}$ analyzed before.

In Fig. 5, we can observe some examples of the recovered information from the package when the percentage stored of FP is only the $30 \%$, and for $\mathrm{N}=729$.

In this second case, the efficiency reached by the process gives us an average value $E_{c}=86.4 \%$.
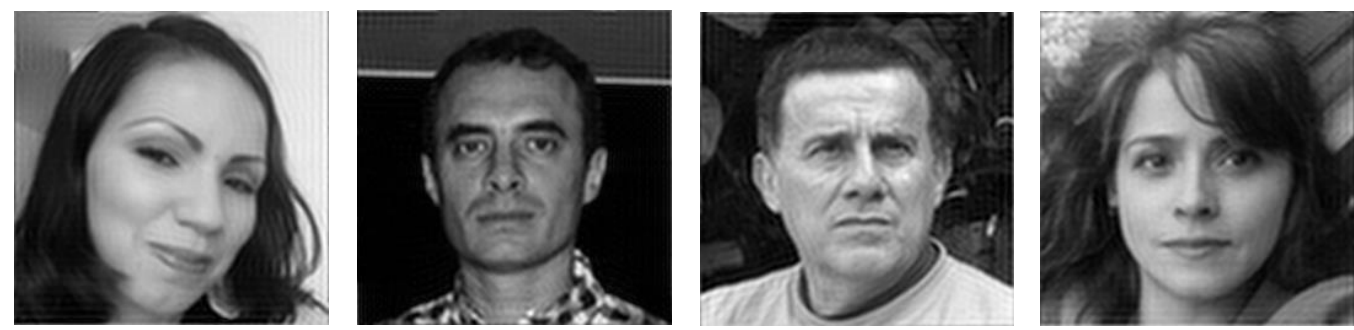

Fig. 5. Examples of recovered images storing $30 \%$ of FP of package, for a number of images in package $\mathrm{N}=729$. Source: Author.
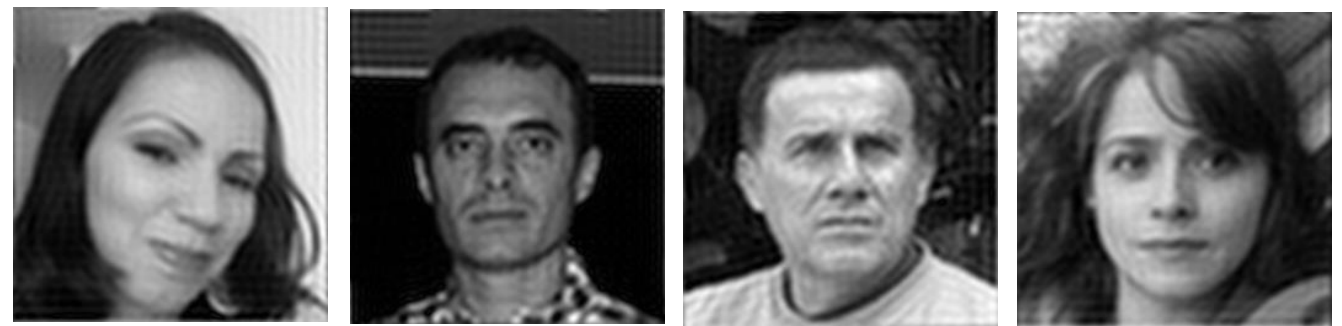

Fig. 6. Examples of recovered images storing $20 \%$ of FP of package, for a number of images in package $\mathrm{N}=729$. Source: Author. 


\subsection{Case 3. Filtering $20 \%$ of FP}

In this case, we only store $20 \%$ of the FP. Again, having the parameters NA = 4096, NUQ $=255, \mathrm{NF}=255$. The stored package is saved in PNG format with 8 bitdepth. Again, we see the decreasing of the $C C$ factor and the increasing of the storage memory savings. The results of this case are summarized in Table 4, where we can see the memory savings achieved at the expense of the quality of the recovered information.

\begin{tabular}{ccccc}
$\begin{array}{l}\text { Table } \\
\text { 4. Summary of memory saving reached and quality } \\
\text { factors of recovered images, storing } 20 \% \text { of FP. } \\
\text { Source: Author. }\end{array}$ \\
\hline $\mathrm{N}$ & $V_{M}(\mathrm{~KB})$ & $\Sigma V_{i}(\mathrm{~KB})$ & $\mathrm{S}(\%)$ & $\overline{C C}$ \\
\hline 49 & 108 & 1764 & 93,88 & 0.979 \\
121 & 261 & 4368 & 94,02 & 0.979 \\
225 & 478 & 8124 & 94,12 & 0.979 \\
361 & 754 & 12944 & 94,17 & 0.979 \\
529 & 1090 & 18992 & 94,26 & 0.979 \\
721 & 1488 & 24912 & 94,03 & 0.979 \\
\hline
\end{tabular}

In the Fig. 6, we can see some examples of recovered images for the case in which we filter the $20 \%$ of $\mathrm{FP}$, and for $\mathrm{N}=729$.

In this third case, the efficiency reached by the method gives us an average value $E_{c}=92.2 \%$.

In all analyzed cases, the values $\overline{C C}$ and $\mathrm{S}$ remain almost constant as $\mathrm{N}$ increases. In this sense, what can be seen in the method is that the only limit in the $\mathrm{N}$ number of images in the package, is given for a very large number $\mathrm{N}$, by computational resources, but with the modern availability of this kind of resources, this does not represent a very serious problem for the implementation of the method; in fact, it is an advantage.

\section{CONCLUSIONS}

We have proposed a virtual optical multiplexing method, based on theta modulation, which uses PDG phase gratings to multiplex and demultiplex information, optimizing pixel values for the amplitude and phase images of the package. The efficiency of the method has been demonstrated to achieve a significant saving of storage memory, while high quality values are obtained for the recovered information, which evidences that neither the saving percentage nor the $\overline{C C}$ quality factor depend on the number of $\mathrm{N}$ images in the package; they only depend on the percentage of the FP stored. The results reported in Tables 2,3 and 4 , in relation to the number of $\mathrm{N}$ images in the package, the average $\mathrm{CC}$ quality factor and the percentage of storage memory savings, represent substantial improvements to the work reported so far in this area of opticalvirtual multiplexing, and these results can be compared with the same terms shown in the introduction of this article. In case 1 , in which $40 \%$ of the FP is stored, 729 images are packaged, achieving a storage memory saving of $78.4 \%$, while the average CC quality factor is always higher than 0.992, and their efficiency factor is $E_{c}=77.9 \%$. In the case of the storage of $20 \%$ of the FP, a memory saving of $94 \%$ is achieved, while the images still remain perfectly recognizable although their average CC value decreases to 0.979 , and their efficiency factor is $E_{c}=92.2 \%$. On the other hand, in all cases the NRMSE quality factor is less than 0.1 , which can also be compared with cited publications.

The perspectives of the method application are broad, and they include: encryption and multiplexing of images, videos, and their application to data processing in general, as an alternative to reach substantial memory savings.

\section{ACKNOWLEDGMENTS}

The author wish to thank to ITM for economical support and for computational resources of the HPC cluster from Parque I, and to MSc Luz Carime Carmona for her advising. 


\section{REFERENCES}

[1] A. Alfalou and C. Brosseau, "Optical image compression and encryption methods," $A d v$. Opt. Photonics, vol. 1, no. 3, p. 589, Nov. 2009.

[2] X. Yong Liang, Z. Xin, Y. Sheng, and C. Yao Yao, "Multiple-image parallel optical encryption,” Opt. Commun., vol. 283, no. 14, pp. 2789-2793, Jul. 2010.

[3] L. Cabezas, M. Tebaldi, J. F. Barrera, N. Bolognini, and R. Torroba, "Optical smart packaging to reduce transmitted information," Opt. Express, vol. 20, no. 1, p. 158, Jan. 2012.

[4] L. Cebezas, M. Tebaldi, J. Barrera, N. Bolognini, and R. D. Torroba, "Image enhancement in multiplexed data by using phase gratings in theta modulation encrypting techniques," in Frontiers in Optics 2012/Laser Science XXVIII, 2012, p. FW3A.11.

[5] B. M. Hennelly, T. J. Naughton, J. McDonald, J. T. Sheridan, G. Unnikrishnan, D. P. Kelly, and B. Javidi, "Spread-space spread-spectrum technique for secure multiplexing," Opt. Lett., vol. 32, no. 9, p. 1060, May 2007.

[6] N. Singh and A. Sinha, "Chaos based multiple image encryption using multiple canonical transforms," Opt. Laser Technol., vol. 42, no. 5, pp. 724-731, Jul. 2010.

[7] X. Wang and D. Zhao, "Multiple-image encryption based on nonlinear amplitudetruncation and phase-truncation in Fourier domain," Opt. Commun., vol. 284, no. 1, pp. 148-152, Jan. 2011.

[8] W. Liu, Z. Xie, Z. Liu, Y. Zhang, and S. Liu, "Multiple-image encryption based on optical asymmetric key cryptosystem," Opt. Commun., vol. 335, no. 0, pp. 205-211, Jan. 2015.

[9] A. Alfalou, C. Brosseau, and N. Abdallah, "Simultaneous compression and encryption of color video images," Opt. Commun., vol. 338, no. 0, pp. 371-379, Mar. 2015.

[10] R. Henao, E. Rueda, J. F. Barrera, and R. Torroba, "Noise-free recovery of optodigital encrypted and multiplexed images," Opt. Lett., vol. 35, no. 3, p. 333, Feb. 2010.

[11] J. J. Huang, H.-E. Hwang, C. Y. Chen, and C. M. Chen, "Optical multiple-image encryption based on phase encoding algorithm in the Fresnel transform domain," Opt. Laser Technol., vol. 44, no. 7, pp. 22382244, Oct. 2012.
[12] X. Deng and D. Zhao, "Multiple-image encryption using phase retrieve algorithm and intermodulation in Fourier domain," Opt. Laser Technol., vol. 44, no. 2, pp. 374377, Mar. 2012.

[13] H. Zhao, J. Liu, J. Jia, N. Zhu, J. Xie, and Y. Wang, "Multiple-image encryption based on position multiplexing of Fresnel phase," Opt. Commun., vol. 286, no. 0, pp. 85-90, Jan. 2013.

[14] H. E. Hwang, H. T. Chang, and W. N. Lie, "Multiple-image encryption and multiplexing using a modified Gerchberg-Saxton algorithm and phase modulation in Fresneltransform domain," Opt. Lett., vol. 34, no. 24, p. 3917, Dec. 2009.

[15] H. T. Chang, H.-E. Hwang, and C.-L. Lee, "Position multiplexing multiple-image encryption using cascaded phase-only masks in Fresnel transform domain," Opt. Commun., vol. 284, no. 18, pp. 4146-4151, Aug. 2011.

[16] J. D. Armitage and A. W. Lohmann, "Theta Modulation in Optics," Appl. Opt., vol. 4, no. 4, p. 399, Apr. 1965.

[17] F. Mosso, J. F. Barrera, M. Tebaldi, N. Bolognini, and R. Torroba, "All-optical encrypted movie," Opt. Express, vol. 19, no. 6, p. 5706, Mar. 2011.

[18] J. F. Barrera, S. Trejos, M. Tebaldi, and R. Torroba, "Experimental protocol for packaging and encrypting multiple data," $J$. Opt., vol. 15, no. 5, p. 55406, May 2013.

[19] S. Trejos, J. F. Barrera, M. Tebaldi, and R. Torroba, "Experimental opto-digital processing of multiple data via modulation, packaging and encryption," J. Opt., vol. 16, no. 5, p. 55402, May 2014.

[20] J. Vargas, D. Amaya, and E. Rueda, "Digital image compression for a $2 \mathrm{f}$ multiplexing optical setup," J. Opt., vol. 18, no. 7, p. 75701, Jul. 2016.

[21] J. W. Goodman, Introduction to Fourier Optics, 2nd ed. McGraw-Hill, 1996.

[22] X. Yong Liang, X. Su, S. Li, X. Liu, and S. Zeng, "Key rotation multiplexing for multiple-image optical encryption in the Fresnel domain," Opt. Laser Technol., vol. 43, no. 4, pp. 889-894, Jun. 2011.

[23] J. A. V. Valencia, "Optimización de un Sistema de Multiplexado Óptico Virtual y encriptación caótica," Tesis Doctoral. Instituto de Física, Universidad de Antioquia, Medellín, Colombia, 2017. 